\title{
Composição bromatológica de silagens de milho comerciais produzidas no Brasil
}

Faria, T.F.R.@ ; Pinese, F.; Gimenes, F.M.A.; Demarchi, J.J.A.A.; Campos, F.P.; Premazzi, L.M.; Mattos, W.T. e Gerdes, L.

Instituto de Zootecnia, Nova Odessa, Brasil.

PALAVRAS CHAVE ADICIONAIS

Conservaç̃o de forragem.

Ensilagem.

Valor nutritivo.

Zea mays.

\section{RESUMO}

Objetivou-se fazer a análise exploratória dos resultados bromatológicos e uso de modelos para estimativa de nutrientes digestíveis totais das amostras de silagem de milho gerados a partir de 12 anos de análises comerciais do banco de dados do Laboratório de Nutrição Animal do Instituto de Zootecnia (IZ), em Nova Odessa, SP, Brasil. Como critério, utilizou-se dados de amostras de silagens de milho sem nenhum tipo de aditivos presentes no banco de dados do laboratório, somando 220 amostras nos períodos de 2004 a 2015 e agrupados em quatro triênios. Estes foram caracterizados quanto à sua composição bromatológica através da análise estatística descritiva, correlações de Pearson e pela utilização de modelos de estimativas de NDT calculado através de quatro modelos de equações: uma da Universidade de Clemson, uma segundo Harlan e duas segundo Kearl (1 e 2). O valor nutricional das amostras de silagens de milho mostrou-se de qualidade mediana, com valores de FDN (49,2 a $57,2 \%$ da MS) acima do ideal. Todas as equações puderam ser utilizadas na estimativa do NDT (variação de 54,3 a 67,0 nos triênios) sendo que a de Kearl 1 e Clemson apresentaram a maior e a menor variação entre os triênios, respectivamente. O aumento do valor nutritivo e de NDT nos triênios 3 e 4 indica melhoria na qualidade da silagem.

\section{Chemical composition of commercial corn silage produced in Brazil}

\section{SUMMARY}

\section{ADDITIONAL KEYWORDS}

Forage conservation.

Ensilage.

Nutritional value.

Zea mays.

\section{INFORMATION}

\section{Cronología del artículo.}

Recibido/Received: 03.12.2018

Aceptado/Accepted: 24.09.2020

On-line: 15.10 .2020

Correspondencia a los autores/Contact e-mail:

thomas.lipe@yahoo.com.br

\section{INTRODUÇÃO}

Nos últimos 25 anos a produção de silagem de milho de planta inteira tornou-se importante e popular no sistema de produção leiteira mundial (Ferrareto et al., 2018). A intensificação dos sistemas produtivos, fez com que parte dos produtores aderisse à suplementação de volumosos com o uso de forragem conservada, sendo a ensilagem o principal processo adotado para conservação de forragem nas propriedades rurais, sendo que o milho é a principal cultura utilizada (Vi- lela et al., 2016). Neste contexto, gerou-se uma maior demanda para o uso de silagem de milho, que é uma planta que possui alta produtividade e qualidade nutricional (Jaremtchuk et al., 2005, Oliveira et al., 2010). Atualmente a silagem de milho é segundo volumoso mais consumido por vacas leiteiras, quantidade inferior apenas aos capins (Khan et al., 2012, Khan et al., 2015).

Para o atendimento das exigências nutricionais de vacas em lactação há necessidade de melhoria no valor 
nutritivo da silagem ofertada aos animais. A busca de melhores resultados em desempenho animal utiliza a nutrição de precisão que, no caso da silagem de milho, deve estar embasada em dados completos e confiáveis sobre a produção de forragem no campo e o processo de ensilagem e fornecimento aos animais (Ferrareto et al., 2018). Desta forma, o aumento do entendimento sobre os dados de valor nutritivo e a melhoria dos métodos laboratoriais de análises possibilitará melhoria nos modelos de formulação de dietas utilizados atualmente.

Porém, desde os anos 2000 Beegle et al. (2000) apontaram que a carência de dados com informações nutricionais popularizados e de fácil acesso é um dos principais fatores limitantes para a adoção de conceitos modernos de nutrição animal. Esse desafio ainda existe e portanto a criação de bancos de dados nutricionais pode ser um importante incentivo para a modernização do processo produtivo.

O Laboratório de Nutrição Animal do Instituto de Zootecnia (IZ), em Nova Odessa, SP, possui atualmente um banco de dados com as análises bromatológicas realizadas entre os anos de 2004 a 2015, incluindo amostras de silagem de milho oriundas de diversos locais com potencial de uso para caracterização qualitativa dessas silagens. Há uma expectativa de melhoria na qualidade nutricional da silagem de milho no Brasil ao longo dos períodos amostrados, resultado de adoção de tecnologias na confecção de silagens. E ainda que, equações para estimar os nutrientes digestíveis totais (NDT) dos alimentos podem ser usados como indicativos de alterações na energia da silagem de milho ao longo do tempo, visto a maior facilidade de aplicação de equações de NDT em relação à energia líquida (EL) (NRC, 2000).

Objetivou-se realizar uma análise exploratória da composição bromatológica de amostras de silagens de milho pertencentes ao banco de dados do Laboratório de Nutrição Animal do Instituto de Zootecnia no período de 2004 a 2015 e estimar o teor de nutrientes digestíveis totais através de equações publicadas na literatura internacional.

\section{MATERIAL E MÉTODOS}

Os resultados das análises bromatológicas de silagens de milho foram avaliados levando em consideração o período entre os anos de 2004 até 2015. Nesse período o banco de dados acumulou um total de 323 amostras de silagens de milho 220 provenientes de propriedades rurais $(68,1 \%)$ e 103 amostras (31,9\%) provenientes de trabalhos de pesquisas, das quais foram selecionadas para esta a avaliação 220 amostras, apenas aquelas de silagem de milho exclusivas (sem outra forrageira) e sem aditivos. As variáveis utilizadas para avaliação da silagem foram: A matéria seca (MS) foi obtida pela multiplicação entre as matérias secas realizadas (MS55 e MS105) e o resultado dividido por 100. Material mineral (MM), proteína bruta (PB), extrato etéreo (EE), extrativo não nitrogenado (ENN) segundo AOAC (1990) e fibra bruta (FB) fibra em detergente neutro (FDN), nitrogênio em FDN (NFDN) fibra em detergente ácido (FDA), nitrogênio em FDA
(NFDA), lignina (Lig), celulose (Cel), hemicelulose (Hem) segundo Van Soest et al. (1991), e nutrientes digestíveis totais (NDT) realizada pela equação de Kearl 1, segundo KEARL (1982) conforme padrão do Laboratório. Também foram descritas a matéria seca a $55^{\circ} \mathrm{C}$ (MS55) com a amostra seca em estufa após chegada ao laboratório antes da moagem, matéria seca a 105 ${ }^{\circ} \mathrm{C}$ feita após a moagem do material e o valor obtido utilizado para correção de todas as demais variáveis.

As variáveis PB, FB, EE, ENN, MM, FDN, FDA, Cel e Lig estão expressas em percentual (\%) da matéria seca e as variáveis NFDN e NFDA estão expressas em percentual (\%) do nitrogênio (N) total da amostra.

Os dados químico-bromatológicos relativos ao período avaliado foram agrupados em triênios com o objetivo de facilitar a compreensão dos resultados e reduzir o impacto dos diferentes números de amostras nos anos, da seguinte forma: Triênio 1 (2004 a 2006), Triênio 2 (2007 a 2009), Triênio 3 (2010 a 2012) e Triênio 4 (2013 a 2015). Para cálculo do NDT das amostras de silagens de milho quatro modelos de equação foram utilizados e comparados entre si, utilizando-se as informações referentes às 220 amostras do banco de dados do IZ. Foram eles: a equação de Clemson (citada por Medeiros \& Albertini, 2015), as equações de Kearl 1 e 2 (Kearl, 1982) e a equação de Harlan (Harlan et al., 1991), as quais estão a seguir apresentados.

Equação 1: Equação da Universidade de Clemson: $\mathrm{NDT}=93,59-($ FDA $\times 0,936)$

As equações de Kearl 1 e 2, descritas por Kearl (1982), em que utiliza o método Wendee, onde não há fracionamento da porção, sendo:

Equação 2: Equação de Kearl - 1 (Pastagens e Forragens Frescas):

$\%$ NDT $=-21,7656+1,4284 \% \mathrm{~PB}+1,0277 \% \mathrm{ENN}+1,232$ $1 \% \mathrm{EE}+0,4867 \% \mathrm{FB}$

Equação 3: Equação de Kearl - 2 (Silagens de Volumosos):

$\%$ NDT $=-21,9391+1,0538 \% \mathrm{~PB}+0,9736 \% \mathrm{ENN}+3,001$ $6 \% \mathrm{EE}+0,4590 \% \mathrm{FB}$

Equação de Harlan (HARLAN et al., 1991) onde há a integração de energia digestível e a composição de nutrientes da forragem para estimar NDT para vacas secas, sendo:

$$
\begin{gathered}
\text { Equação 4: NDT, \% = 53,1 x (ELL/2,2)+ 31,4 } \\
\text { ELL }=(1,044-(0,0124 \times \text { FDA })) \times 2,2 \\
\text { Em que ELL = energia líquida de lactação. }
\end{gathered}
$$

Foi utilizada uma estatística descritiva, com análise não paramétrica,

utilizando o procedimento Univariate do SAS versão 9.2, com Test de

location e de significância o Teste T para avaliação dos resultados

químico-bromatológicos, dentro de cada triênio. A relação entre frações MS total, PB, EE, ENN, MM, NDT, FDN, FDA NFDN, NFDA Cel e Lig foram feitas pela 
correlação de Pearson, com uso do PROC CORR do pacote estatístico SAS® (Statistical Analysis System), versão 8.2 para Windows® (SAS, 2010) e o coeficiente de correlação descrito quando $\mathrm{P}<0,05$.

Utilizou-se um delineamento inteiramente casualizados, com medidas repetidas no tempo para a avaliação dos modelos de equação de predição dos nutrientes digestíveis totais (NDT) e os triênios avaliados. Analisaram-se os dados num esquema fatorial $4 \times 4$, sendo quatro triênios e utilização de quatros modelos de equações para estimativas do NDT. Utilizou-se do PROC Mixed do pacote estatístico SAS® (Statistical Analysis System), versão 9.4 para Windows® (SAS, 2010) para análises de médias, adotando nível de significância a 5\% pelo teste de Tukey-Kramer.

\section{RESULTADOS}

Na Tabela I são apresentados os valores médios e desvios padrão das amostras avaliadas procedentes do banco de dados do Laboratório de Nutrição Animal do Instituto de Zootecnia agrupados em triênios.

Os valores de MS apresentaram pouca variação numérica entre os Triênios de 92,4 Triênio 2 a 93,5\% no Triênio 4, enquanto uma variação maior foi observada para MS55, de 30,8\% no Triênio 1 a 44,8\% no Triênio 3. A matéria seca original teve seu menor valor no Triênio $1(28,8 \%)$ e maior no Triênio 3 de $(42,9 \%)$. A PB variou de 8,8 no triênio 3 até valor de $12,5 \%$ da MS105 no Triênios 2. Enquanto a fibra bruta apresentou a amplitude de 22,3\% observada no Triênio 3, a 25,9\% no Triênio 2 . O EE teve variação de 2,2 nos Triênios 3 e 4 a 3,5\% no Triênio1. A MM variou de 5,6 no Triênio 1 a 6,9\% no Triênio 2. As frações de fibra FDN e FDA apresentaram valores diferentes entre os triênios, com maior valor de FDN no Triênio 1 (57,2\%) e FDA no Triênio 2 (42,0\%) enquanto os menores valores de FDN estiverem no Triênio $2(49,2 \%)$ e de FDA no Triênio 4 (30,5\%). Os valores de NFDN variaram de 11,9 no Triênio 4 a $16,6 \%$ do $\mathrm{N}$ total da amostra no Triênio 3. Para NFDA houve amplitude de 8,9 no Triênio 4 a 10,2 no Triênio 2 . O teor de celulose variou de 26,2 no Triênio 4 a 28,6\% no Triênio . E para lignina tivermos a menor média no Triênio 4 e a maior no Triênio 1 .

Os dados de Correlação de Pearson entre as variáveis podem ser encontrados na Tabela II. Dentre as correlações significativas e que tiveram seu coeficiente de determinação maior do que 0,5 , destacam-se as correlações positivas entre FDN e demais componentes da fibra, como FDA $(0,87), \operatorname{NFDN}(0,58), \operatorname{NFDA}(0,55)$ e celulose (068). Para proteína bruta houve correlação positiva com EE $(0,74)$ e negativa com ENN $(-0,55)$ e componentes da fibra como NFDN $(-0,61)$ e NFDA $(-0,68)$. Os nutrientes digestíveis totais apresentaram poucas correlações significativas (EE, FDN e Lig) e nenhuma delas com coeficiente de determinação acima de 0,5 .

Os valores médios dos nutrientes digestíveis totais (NDT) calculados por 4 equações são apresentados na Tabela III. Estes foram utilizados para estimar o NDT médio para cada Triênio. Os valores apresentados são originais, porém as diferenças estatísticas são apontadas de acordo com a análise realizada com os dados transformados (NDT=Y2). Houve diferença em relação ao modelo $(P<0,0001)$, Triênio $(<0,0001)$ e interação entre modelo $x$ triênio $(\mathrm{P}=0,0034)$.

Para o Triênio 1 os valores obtidos pelos modelos Harlan, Clemson e Kearl 2 não diferiram entre si e o modelo de Harlan resultou em maior valor em relação ao modelo de Kearl 1. Já para o Triênio 2 o modelo de Kearl 2 apresentou maior valor de NDT, semelhante ao de Clemson, seguido pelo de Harlan e o menor valor

Tabela I. Valores médios e erro padrão da composição químico-bromatológica de amostras de silagem de milho presentes no banco de dados do Instituto de Zootecnia (Mean values and standard error of chemical-bromatological composition of corn silage samples present in the database of the Institute of Animal Science).

\begin{tabular}{|c|c|c|c|c|}
\hline Variáveis & Triênio 1 & Triênio 2 & Triênio 3 & Triênio 4 \\
\hline MS105 & $93,2 \pm 1,12$ & $92,4 \pm 1,51$ & $93,0 \pm 5,94$ & $93,5 \pm 1,35$ \\
\hline MS55 & $30,8 \pm 7,08$ & $31,3 \pm 8,01$ & $44,8 \pm 9,67$ & $41,0 \pm 10,1$ \\
\hline MS & $28,8 \pm 6,72$ & $29,6 \pm 7,58$ & $42,9 \pm 8,58$ & $38,4 \pm 9,6$ \\
\hline PB (\% da MS) & $12,0 \pm 3,68$ & $12,5 \pm 4,34$ & $8,8 \pm 2,16$ & $10,0 \pm 2,72$ \\
\hline FB (\% da MS) & $25,2 \pm 3,07$ & $25,9 \pm 5,27$ & $22,3 \pm 3,86$ & $23,3 \pm 5,35$ \\
\hline EE (\% da MS) & $3,5 \pm 1,41$ & $2,7 \pm 0,83$ & $2,2 \pm 0,42$ & $2,2 \pm 0,56$ \\
\hline ENN (\% da MS) & $61,3 \pm 4,20$ & $57,2 \pm 7,59$ & $59,6 \pm 4,39$ & $57,0 \pm 12,8$ \\
\hline MM (\% da MS) & $5,6 \pm 1,27$ & $6,9 \pm 2,08$ & $5,8 \pm 1,59$ & $6,4 \pm 1,6$ \\
\hline FDN (\% da MS) & $57,2 \pm 6,53$ & $49,2 \pm 12,28$ & $53,8 \pm 3,88$ & $53,0 \pm 8,1$ \\
\hline FDA ( $\%$ da MS) & $35,4 \pm 4,88$ & $42,0 \pm 17,46$ & $32,2 \pm 2,83$ & $30,5 \pm 3,8$ \\
\hline NFDN (\% do N) & $14,8 \pm 4,20$ & $16,2 \pm 1,1$ & $16,6 \pm 4,78$ & $11,9 \pm 2,01$ \\
\hline NFDA (\% do N) & $8,6 \pm 2,69$ & $10,2 \pm 0,76$ & $9,8 \pm 3,74$ & $8,9 \pm 0,99$ \\
\hline Cel (\% da MS) & $28,6 \pm 4,21$ & $28,5 \pm 5,55$ & $27,9 \pm 8,35$ & $26,2 \pm 3,46$ \\
\hline Lig (\% da MS) & $5,5 \pm 0,89$ & $4,5 \pm 1,37$ & $4,0 \pm 0,93$ & $3,0 \pm 0,80$ \\
\hline
\end{tabular}

Triênios: 1, 2004 a 2006, 2, 2007 a 2009, 3, 2010 a 2012, 4, 2013 a 2015 dos triênios 1, 3 e 4. Triênio 2, Pr> t de 0,0304 para NFDN, 0,0338 para NFDA e 0,0005 para Lig e demais variáveis com $\mathrm{P}<0,0001, \mathrm{Pr}=$ probabilidade 
foi obtido pelo modelo de Kearl 1 que diferiu dos demais. Para o Triênio 3 os modelos de Kearl 2, Clemson e Harlan não diferiram entre si e tiveram os maiores valores e o modelo de Kearl 1 apresentou o menor valor. Para o Triênio 4 os modelos com maiores valores foram Kearl 2, Harlan e Kerl 1, este não diferiu dos demais, e o menor valor foi para o modelo de Clemson.

Para o modelo de Kearl 1, os Triênios 3 e 4 tiveram os maiores valores, seguidos do Triênio 1 e Triênio 2, que tiveram o menor valor. Já para o modelo de Kearl 2 e Clemson não houve diferença entre os Triênios. Para o modelo de Harlan, apenas o Triênio 2 diferiu dos demais e apresentou NDT inferior.

\section{DISCUSSÃO}

As médias dos teores de MS observados variam com os Triênios analisados (Tabela I), fato esse provavelmente devido ao grande variabilidade na origem das amostras e fatores de produção e processamento, armazenamento e envio do material. Parte das amostras foi enviada por pesquisadores que utilizaram silagem de milho em projetos de pesquisa e outra e em parte por produtores rurais, de diversas regiões do país. Além disso, outros fatores como ponto de corte da planta de milho para ensilagem, híbrido utilizado, tipo de silo usado para armazenamento e densidade de armazenamento podem contribuir para as variações

\begin{tabular}{|c|c|c|c|c|c|c|c|}
\hline \multirow[b]{2}{*}{ Modelos } & \multicolumn{4}{|c|}{ Triênios } & \multicolumn{3}{|c|}{ P-valor } \\
\hline & 1 & 2 & 3 & 4 & Mod. & Trien. & Int. \\
\hline & \multicolumn{4}{|c|}{ NDT, \% * } & & & \\
\hline Kearl 1 (1982) & $63,3 \pm 0,45 \mathrm{Bb}$ & $54,3 \pm 1,64 \mathrm{Cc}$ & $63,8 \pm 0,59 \mathrm{ABb}$ & $65,4 \pm 0,57 \mathrm{Aab}$ & $<0,0001$ & $<0,0001$ & 0,0034 \\
\hline Kearl 2 (1982) & $66,5 \pm 1,64 \mathrm{AAab}$ & $65,8 \pm 1,24 \mathrm{AAa}$ & $66,9 \pm 0,72 \mathrm{Aa}$ & $66,2 \pm 0,95 \mathrm{Aa}$ & & & \\
\hline $\begin{array}{l}\text { Clemson Uni- } \\
\text { versity (USA) }\end{array}$ & $63,3 \pm 1,64$ AAab & $63,4 \pm 1,24 \mathrm{AAab}$ & $63,1 \pm 0,71 \mathrm{Ab}$ & $63,2 \pm 0,95 \mathrm{Ab}$ & & & \\
\hline $\begin{array}{l}\text { Harlan et al., } \\
\text { (1991), }\end{array}$ & $65,6 \pm 0,45 \mathrm{AAa}$ & $59,2 \pm 1,64 \mathrm{Bb}$ & $65,9 \pm 0,59 \mathrm{Aa}$ & $67,0 \pm 0,57 \mathrm{Aa}$ & & & \\
\hline
\end{tabular}

a, b, c: médias seguidas de letras diferentes, minúsculas, sobrescritas nas colunas foram significativas a $P<0,05$ pelo teste Tukey. A, B, C: médias seguidas de letras diferentes, maiúsculas, sobrescritas nas linhas foram significativas a $P<0,05$ pelo teste Tukey. NDT $=\mathrm{Y}^{2}$. Mod. = modelo de equações de estimativa dos nutrientes digestíveis totais (NDT). Int.= efeito interação, Trien. = triênios, 1: 2004-2006, 2: 2007-2009, 3: 2010-2012 e 4: 2013- 2015, EPM = erro padrão da média.

observadas nas médias de MS apresentadas (Tabela I). O intervalo de matéria seca ideal no material a ser ensilado situa-se no intervalo de 28 a 37\% segundo (Nussio, 1991, Cruz, 1998). Segundo Khan et al. (2015), milho ensilado abaixo de $25 \%$ de matéria seca (MS) há redução no teor de amido e amido/FDN resultando em menor consumo e desempenho animal, este cresce até $35 \%$ de MS no material ensilado e volta à ser reduzido.

As médias de proteína bruta (PB) encontradas nos triênios variaram entre valores de 8,8 a $12,5 \%$ (Tabela I), valores estes superiores aos encontrados por Valadares Filho et al. (2002), entre 6,0 e 8,6\% de PB e próximos aos encontrados por Villela (2001), de 6,7 a 8,0\%. Em duas densidades de compactação (500 e $600 \mathrm{~kg} / \mathrm{m} 3$ ) de matéria verde os teores de proteína encontrados na silagem foram de $8 \%$ (Velho et al., 2007). Esses resultados mostram que os teores de proteína bruta determinados nas amostras estão dentro do padrão apresentado na literatura científica, o que foi importante de constatar, pois dão um importante indicativo da qualidade da silagem, sendo que a fração protéica é o componente mais caro da ração. Segundo Mertens (1994), os valores mínimos de PB aceitos como limitante do crescimento microbiano para manter a fermentação ruminal são de $7 \%$. Ainda, no presente levantamento os teores observados de proteína bruta apresentaram-se acima do valor de $7 \%$ em todos os triênios, indicando o bom aporte de PB da silagem na dieta dos animais.

Os resultados de PB foram utilizadas para cálculo nas equações de NDT de Kearl 1 e 2 , e interferem de forma positiva no valor de NDT, apesar de PB não ter sido significativamente correlacionada à estimativa de NDT (Tabela II).Os valores de NFDN e NFDA indicam os percentuais de nitrogênio presentes nas frações da parede celular e estiveram negativamente correlacionados aos valores de PB (Tabela II).

Os teores médios de extrato etéreo (EE) na silagem estiveram entre 2,2 e 3,5\% (Tabela I) e encontram-se dentro da faixa de valores encontrados na literatura, que variam de 2,1 a 3,8\% (Pires et al., 2010, Khan et al., 2012), e que são considerados valores adequados a uma boa silagem de milho. Lavezzo et al. (1997b) estudando estádio de desenvolvimento da planta do milho para silagem, encontraram maior concentração de extrato etéreo em plantas com grãos no ponto leitoso e ponto de pamonha quando comparados com grãos no ponto farináceo e semi-duro, respectivamente, novamente reforçando o efeito do da maturidade das plantas de milho no momento da colheita nos parâmetros bromatológicos da forragem.

As médias de valores do extrativo não nitrogenado (ENN) obtidas do banco de dados do Laboratório de Nutrição Animal variaram de 57,0 a 61,3\%. A amplitu- 


\begin{tabular}{|c|c|c|c|c|c|c|c|c|c|c|c|c|}
\hline & MS & PB & EE & ENN & MM & NDT & FDN & FDA & NFDN & NFDA & Cel & Lig \\
\hline MS & 1,00 & $0,47^{* *}$ & $-0,20^{*}$ & NS & $0,37^{* *}$ & NS & $-0,47^{* *}$ & $-0,53^{* *}$ & $-0,62^{* *}$ & $-0,58^{* *}$ & $-0,59^{* *}$ & NS \\
\hline PB & $0,47^{\star *}$ & 1,00 & $0,74^{* *}$ & $-0,55^{\star *}$ & $0,30^{* *}$ & NS & $-0,44^{* *}$ & $-0,35^{\star *}$ & $-0,61^{\text {** }}$ & $-0,68^{* *}$ & $-0,49^{* *}$ & NS \\
\hline EE & $-0,20^{*}$ & $0,74^{* *}$ & 1,00 & NS & NS & $0,25^{\star}$ & $-0,37^{* *}$ & $-0,18^{* *}$ & $-0,43^{* *}$ & $-0,52$ & $-0,33^{* *}$ & NS \\
\hline ENN & NS & $-0,55^{\star *}$ & NS & 1,00 & $-0,55^{\star *}$ & NS & $-0,53^{* *}$ & $-0,70^{* *}$ & NS & $-0,35^{* *}$ & $-0,46^{* *}$ & NS \\
\hline MM & $0,37^{* *}$ & $0,30^{* *}$ & NS & $-0,55^{\text {** }}$ & 1,00 & NS & $-0,22^{* *}$ & NS & NS & $-0,20^{*}$ & NS & $-0,16^{*}$ \\
\hline NDT & NS & NS & $0,25^{*}$ & NS & NS & 1,00 & $-0,33^{*}$ & NS & NS & NS & NS & $0,02^{* *}$ \\
\hline FDN & $-0,47^{* *}$ & $-0,44^{* *}$ & $-0,37^{* *}$ & $-0,53^{* *}$ & $-0,22^{* *}$ & $-0,33^{*}$ & 1,00 & $0,87^{* *}$ & $0,58^{* *}$ & $0,55^{\star *}$ & $0,68^{* *}$ & $0,28^{* *}$ \\
\hline FDA & $-0,53^{* *}$ & $-0,35^{\star *}$ & $-0,18^{* *}$ & $-0,70^{* *}$ & NS & NS & $0,87^{* *}$ & 1,00 & $0,56^{\star *}$ & $0,54^{* *}$ & $0,71^{* *}$ & $0,47^{* *}$ \\
\hline NFDN & $-0,62^{* *}$ & $-0,61^{\text {** }}$ & $-0,43^{* *}$ & NS & NS & NS & $0,58^{* *}$ & $0,56^{\star *}$ & 1,00 & $0,79^{* *}$ & $0,51^{* *}$ & NS \\
\hline NFDA & $-0,58^{* *}$ & $-0,68^{* *}$ & $-0,52^{\star *}$ & $-0,35^{*}$ & $-0,20^{*}$ & NS & $0,55^{\star *}$ & $0,54^{\star *}$ & $0,79^{* *}$ & 1,00 & $0,49^{* *}$ & NS \\
\hline Cel & $-0,59^{* *}$ & $-0,49^{* *}$ & $-0,33^{* *}$ & $-0,46^{*}$ & NS & NS & $0,68^{* *}$ & $0,71^{* *}$ & $0,51^{* *}$ & $0,49^{* *}$ & 1,00 & $-0,21^{* *}$ \\
\hline Lig & NS & NS & NS & NS & $-0,16^{*}$ & NS & $0,28^{* *}$ & 0,47 & NS & NS & $-0,21^{\text {** }}$ & 1,00 \\
\hline
\end{tabular}

de de valores encontrada está de acordo com silagens de milho reportadas na literatura como de $56,7 \%$ por Possenti et al. (2005). Já Alfaya et al. (2009) trabalhando com duas recomendações de adubação uma para grãos e outra para silagens obteve o teor máximo de ENN na silagem de milho quando adubada para grãos sendo este teor de $64,8 \%$, provavelmente devido á maior proporção de grãos na massa ensilada. Segundo Hall (2003) o extrativo não nitrogenado corresponde, teoricamente, aos carboidratos não estruturais ou conteúdo celular das forrageiras (amido, açúcares, pectinas, etc.) que são indicativos de valor energético. Pode ser superestimado, uma vez que na Tabela II apresentou correlação não significativa com os valores de NDT calculados no Laboratório de Nutrição Animal.

Os valores médios de fibra em detergente neutro (FDN) na silagens de milho variaram de 49,2 a 57,2\% (Tabela I), sendo que o Triênio 1 apresentou o maior valor, com valores inferiores nos demais Triênios. Esse resultado pode ter ocorrido devido à alteração genética dos cultivares de milho destinados a produção de silagem e à melhoria na tecnologia empregada na confecção da silagem.

A fração da silagem de milho composta pela parede celular, chamada de fração fibrosa e, normalmente analisada como FDN e composta de celulose, hemicelulose, lignina, alguma contaminação de pectina, proteína e cinzas, é importante para o bom funcionamento do rúmen e determinante de consumo de alimentos volumosos. Porém, o excesso de fibras limita o consumo desses animais pelo preenchimento físico no rúmen. Considerando o consumo a principal condição para o desempenho animal, a proporção de FDN deve ser limitada nas silagens, bem como ter alta digestibilidade (Kramer-Schimid et al., 2016).

Qiu et al. (2003) e Fernandez et al. (2004) concluíram que dietas contendo silagem de milho com teores de FDN entre 37 e $45 \%$ na MS, valores estes abaixo das médias encontradas neste trabalho, oferecidas a vacas de leite e de novilhos de corte, proporcionaram maior ingestão de alimentos em relação às que apresentavam silagem de milho com teores mais altos de FDN e, consequentemente melhores desempenhos. Os valores de FDN estiverem positivamente correlacionados com os demais componentes de parede celular (FDA, Cel Lig, NFDN e NFDA) e negativamente correlacionados com os teores de PB $(-0,44)$, EE $(-0,37)$, ENN $(0,53)$ e com NDT $(-0,33)$, apesar do baixo coeficiente de correlação, indicando que os maiores teores de FDN tendem a resultar em menor energia digestível na silagem.

Os resultados apresentados pelas amostras de silagem de milho recebidas pelo Laboratório nos dão indícios de que as plantas de milho foram colhidas com maturação superior aos pontos de colheita como descritos por Andrade et al. (2001) que avaliaram dois pontos de colheita baseados na linha de leite (1/2 e 1) , ou seja, 50\% da linha de leite e linha negra atingindo um teor de FDN na silagem de milho de 41,9 e 45,7\%, respectivamente. Esse fato corrobora a afirmação de Khan et al. (2015), onde em trabalho de revisão de 13 artigos conclui que as maiores variações no valor nutritivo de silagens de milho são atribuídos à diferenças na maturidade da cultura no momento da colheita (Khan et al., 2015). Além do ponto de colheita, Restle et al. (2002) sugerem que um processo eficiente a ser usado para diminuir o teor de FDN na silagem é a elevação da altura de corte da planta de milho, que aumenta a proporção de grãos em detrimento de colmos e folhas senescentes.

Os teores médios de fibra em detergente ácido (FDA) descritos nas amostras de silagem variam entre 30,0 e $42,0 \%$ (Tabela I) da MS105 e são um indicativo da digestibilidade do alimento (Wattiaux \& Karg, 2006), pois é composta de celulose e lignina. Segundo Lavezzo et al. (1997) os teores considerados ideais encontram-se no intervalo situado entre de 30,5 a 37,7\%, valores próximos aos encontrados no banco de dados do IZ, exceto no Triênio 2 com valores médios de 42,0\% (Tabela I). Villela (2001) apontou teores de FDA na silagem de milho mais baixos, entre 23,9 e 27,1\% quando as plantas de milho foram colhidas em $50 \%$ da linha do leite e linha negra, respectivamente, indicando, assim como para o FDN, o ponto de colheita médio da forra- 
gem de milho para as amostras de silagem presentes no banco de dados do IZ corresponderia a um estado de maturidade mais adiantado aos apontados por este autor.

A fração FDA também importante por se considerada em equações para estimativa de NDT, como as equações de Clemson e de Harlan. Apesar desse fato, nas correlações apontadas na Tabela II não apresentou correlação significativa com NDT, provavelmente porque o NDT calculado pelo Laboratório de Nutrição Animal usou a equação de Kearl 1 para suas estimativas e nesta equação não há fracionamento da fibra, sendo utilizada a fibra bruta (FB). Dessa forma, não há como estabelecer essa correlação de parte da fibra em relação aos resultados de NDT.

O manejo da colheita também afeta os teores de FDA, Hutjens (2000), identificou que para cada $15 \mathrm{~cm}$ na elevação da altura de corte da planta de milho é esperado redução de $1 \%$ no teor de FDA do material colhido. Assim, tem se buscado silagens com menores teores de fibra e com fibras de alta digestibilidade. No entanto, algumas pesquisas com genótipos de milho com teores excessivamente baixos de fibra têm gerado problemas com acamamentos, sobretudo em regiões de ventos constantes.

Segundo Van Soest (1994) altos teores de NFDN podem ser explicados pela possível complexação do tanino dos grãos com a proteína. Segundo Rodrigues et al. (2002) teores de NFDA possuem nível de referência de $8 \%$ do $\mathrm{N}$ total como limite para indicar superaquecimento dos alimentos. Contudo, uma silagem bem preparada de milho possui NFDA abaixo de 12\% (Roth \& Undersanders, 1995), o que indica um processamento adequado durante o processo de ensilagem das amostras. Segundo Van Soest (1994) a proteína reage com os carboidratos da planta, passando a fazer parte da fração FDA, este processo é chamado de Reação de Maillard, aumentando assim o NFDA da silagem. Valores mais elevados a $8 \%$ NFDA observados nas amostras do banco de dados do IZ, podem ter sido ocasionados por aquecimento da silagem durante o processo de conservação. Silagens obtidas na superfície tiveram menor teor de NFDA que aquelas obtidas a média profundidade (Rodrigues et al, 2002), indicando efeitos do aquecimento no interior do silo. $\mathrm{Ou}$ ainda que a alta concentração de NFDA seja inerente a forrageiras cultivadas em clima tropical.

$\mathrm{O}$ teor nitrogênio ligado à fibra detergente ácido (NFDA) variou de 8,6 a 10,2\% do nitrogênio total (Tabela I). As médias de teores de nitrogênio ligado à fibra detergente ácido (NFDN) encontradas nas amostras de silagem variaram de $11,9 \%$ a $16,6 \%$ do nitrogênio total (Tabela I). Segundo Van Soest (1994) o NFDN é digestível, porém de lenta degradação no rúmen, enquanto o NFDA é praticamente indigestível e geralmente esta associado à lignina e a outros compostos de difícil degradação.

A média da celulose observada nas amostras de silagem, entre 26,2 e 28,6\% (Tabela I) está um pouco acima da faixa de teores mais comumente encontrados em silagens de boa qualidade, que variam entre 25,5 a $27,0 \%$ de celulose na MS. Possenti et al. (2005) obtive- ram valores médio de $27 \%$ de celulose em silagem de milho, valores similares aos do banco de dados.

Os teores médios de lignina entre 3,0 e 5,5\% (Tabela I) observados nas amostras de silagem ficaram abaixo dos encontrados por Rosa et al. (2004), cujo valores estiveram entre 4,79 a 5,96\% da MS, avaliando três híbridos. O teor de lignina da forragem é importante de ser caracterizado pois relaciona-se inversamente com a digestibilidade dos alimentos. $\mathrm{O}$ teor de lignina na forragem varia com a maturidade da planta, pois quanto mais avançada a idade da planta mais lignificada ela será. A quantidade de folhas em relação ao colmo também tem influencia, pois se sabe que as folhas apresentam uma menor concentração de FDA e lignina quando comparados ao colmo (Van Soest, 1994). Segundo Caballero et al. (2001) a fração indisponível (C) depende do teor de lignina e o aumento desta fração promove redução da fração potencialmente degradável (B2).

Houve variação nos valores de NDT calculados com diferentes modelos (Tabela III). E houve interação entre modelo e triênio, mostrando um padrão de variação inconstante com valores maiores ou menores conforme o triênio dentre de um mesmo modelo. A maior variação ocorreu no modelo de Kearl 1, seguido de Harlan, enquanto os modelos de Kearl 2 e Clemson tiveram pouca variação de resultados de NDT. Os resultados mostram que não basta a fórmula utilizar a mesmas variáveis, mas os coeficientes atuam alterando o impacto de cada componente no valor final do NDT. Tanto os modelos de Clemson quanto Harlan são baseados nos cálculos de apenas um componente químico, o FDA, o que torna essas equações mais simplistas. Nesse contexto seria esperado que os resultados de NDT variassem de forma semelhante em ambas as equações baseadas em FDA. Da mesma forma, dentre as equações propostas por Kearl (1982) ambas utilizam as mesmas variáveis, mas a equação Kearl 1 foi a que teve maior variação no NDT nos triênios.

O NDT é um dos modos mais empregados na expressão de energia, e primeiramente foi calculado com a soma das frações digestíveis dos alimentos de acordo com a análise de Weende. Porém essa abordagem apresenta varias limitações, tais como considerar apenas perdas digestivas de alimentos, incorporar imperfeições na análise proximal (Weende), superestima alimentos fibrosos e subestima concentrados podendo colocar parte da lignina e hemicelulose solubilizadas como parte do ENN, dentre outros. O NDT é medido em experimentos onde são pesados e analisados pela análise de Weende todo o alimento consumido e todas as fezes.

Para facilitar seu uso, o NDT pode ser estimado por meio de equações que facilitam o processo, porém tem baixa acurácia, pois são bastante dependentes da adequação do alimento aos componentes da equação. Neste contexto, Kearl (1982) desenvolveu cinco equações conforme o tipo de alimento: a) Feno, palha e resíduos fibrosos secos, b) Pastagens e forragens frescas, c) Silagens e volumosos, d) Alimentos energéticos e e) Suplementos protéicos. Duas delas, a equação b) e 
c) estão sendo avaliadas no presente trabalho com a denominação de Kearl 1 e Kearl 2, respectivamente.

Variáveis na obtenção da silagem, considerando corte e processamento da cultura de milho, cultivares e outros podem impactar no valor de NDT obtido com a silagem. Caetano (2001) verificou que a elevação da altura de corte melhorou a qualidade da forragem, em decorrência da redução da participação das frações colmo e folhas, havendo como consequência a redução dos componentes da parede celular e aumento nas proporções de grãos, o que determinou o aumento nos valores de NDT. Tedeschi et al. (2002) encontrou valores médios de NDT de $65,4 \%$ para silagens de milho produzidas no Brasil. Velho et al. (2007) encontraram valores parecidos quando compararam níveis de compactação no silo alta e média com cerca de $69 \%$ de NDT. Costa et al. (2000) analisando silagens de milho com diferentes porcentagens de espigas potencialmente comercializáveis, observou que as plantas $100 \%$ inteiras continham maior NDT, devido à proporção de grãos, os quais possuem maior concentração de energia em relação à fração volumosa.

De modo geral o último triênio apresentou médias superiores para NDT e menores para FDN, FDA, NFDN, NFDA e medianos de PB, possivelmente pelo uso de novos cultivares de milho, colheita da planta no momento correto e avanço nas técnicas de ensilagem, armazenamento e desensilagem.

\section{CONCLUSÃO}

Houve aumento no valor nutritivo das silagens enviadas ao Laboratório ao longo dos anos As quatro equações podem ser utilizadas para estimar os valores de NDT, porém para silagens de milho para alimentação de ruminantes as equações de Clemson e Harlan são mais indicadas.

\section{AGRADECIMENTOS}

À Dra. Rosana Aparecida Possenti e ao Laboratório de Nutrição Animal do Instituto de Zootecnia e sua equipe pela disponibilização dos dados e auxilio.

\section{BIBLIPGRAFÍA}

Alfaya, H., Santos. L.A, Raupp. A.A.A.,Lüder. W.E., Rodrigues.R.C., \& Reis. J.C.L. Avaliação de silagens elaboradas com milho produzido sob dois níveis de adubação: II qualidade. Pesquisa Agropecuária Gaúcha, v.15, p.123-133, 2009.

Andrade, J.G., Hunt, C.W., \& Pritchard, G.T.Effect of hybrid, maturity and mechanical processing of corn silage on intake and digestibility by beef cattle. Journal of Animal Science, v.79, p.2268-2275, 2001.

Beegle, D.B., Carton, O.T., \& Bailey, J.S. Nutrient management planning: justification, theory, practice. Journal of Environmental Quality, v.29, p.72-79, 2000.

Caballero, R., Alzueta, C., Ortiz, L.T., Rodríguez, M. L., Barro, C., \& Rebolé, A. Carbohydrate and protein fractions of fresh and dried Common Vetch at three maturity stages. Agronomy Journal, v.93, p.1006-1013, 2001.

Caetano, H. Avaliação de onze cultivares de milho colhidos em duas alturas de corte para produção de silagem, 2001, 178p, Tese (Doutorado em Zootecnia) - Faculdade de Ciências Agrárias e Veterinárias, Universidade Estadual Paulista, Jaboticabal, 2001.
Costa, C., Creste, C.R., Arrigoni, M.D.B., Silveira, A. C., de Magalhães Rosa, G. J., \& Bicudo, S. J.. Potencial para ensilagem, composição química e qualidade da silagem de milho com diferentes proporções de espigas. Acta Scientiarum, v.22, n.3, p.835-841, 2000.

Cruz, J. C. Cultivares de milho para ensilagem. In: CONGRESSO NACIONAL DOS ESTUDANTES DE ZOOTECNIA, 1998, Viçosa, MG. Resumos...Viçosa: UFV. p.93-114, 1998.

Fernandez, I., Nozière, P., \& Michalet-Doreau, B. Site and extent of starch digestion of whole-plant maize silages differing in maturity stage and chop length, in dairy cows. Livestock Production Science, v.89, p.147-157, 2004.

Ferraretto, L. F, Shaver, R. D., \& Luck, B. D. Silage review: Recent advances and future technologies for whole-plant and fractionates corn silage harvesting. Jounal of Dairy Science. v. 101, p.3937-3951, 2018.

Hall, M. B. Challenges with nonfiber carbohydrate methods 12 . Journal of animal science, v. 81, n. 12, p. 3226-3232, 2003.

Harlan, D. W. , Holter, J.B., \& Hayes, H.H. Detergent fiber traits to predict productive energy of forages fed free choice to nonlactating dairy cattle. Journal of Dairy Science, Volume 74, p1337-1353, 1991. http://dx.doi.org/10.3168/jds.S0022-0302(91)78289-1

Hutjens, M. "Selecting corn silagevarieties." 2000. Disponível em: <http:// livestocktrail.illinois.edu/dairynet/paperDisplay.cfm?ContentID=577>. Acesso em: 24 jul. 2018.

Instituto Brasileiro De Geografia E Estatística. Censo agropecuário 2015. Rio de Janeiro, 2015. Disponívelem:http://www.ibge.gov.br/ home/estatistica/indicadores/agropecuaria/producaoagropecuaria/ default.shtm\#animal. Acesso em: 17 out. 2015

Jaremtchuk, A.R., Jaremtchuk, C.C., Baglioli, B., Medrado, M.T., Kozlowski, L.A., Costa, C., \& Madeirah, M.F. Características agronômicas e bromatológicas de vinte genótipos de milho (Zea mays L.) para silagem na região leste paranaense. Acta Scientiarum. Animal Science. Maringá, v. 27, n. 2, p. 181-188, 2005.

Kramer-Schimid, M., Lund,P., \& Wisbjerg, M.R. Importance of NDF digestibility of whole crop maize silage for dry matter intake and milk production in dairy cows. Animal Feed Science and Technology, v.219, p.68-76, 2016. https://doi.org/10.1016/j.anifeedsci.2016.06.007

Kearl, L.C. Nutrient requirements of ruminants in developing countries. Lugan, Utah: International Feedstuffs Institute, Utah State University, 1982. $381 \mathrm{p}$.

Khan, N.A, Cone, J.W, Fievez, V, \& Hendriks, W.H. Causes of variation in fatty acid content and composition in grass and maize silages. Animal Feed Science and Technology, v. 174, p.36- 45, 2012.

Khan, N.A., Yu, P., Ali, M., Cone, J. W., \& Hendriks, W. H. Nutritive value of maize silage in relation to dairy cow performance and milk quality. Journal of the Science of Food and Agriculture., v.95, p. 238-252, 2015

Lavezzo, O.E.N.M., Lavezzo, W., \& Siqueira, E.R. Estádio de desenvolvimento do milho e efeito sobre o consumo e a digestibilidade da silagem em ovinos. Revista Brasileira de Zootecnia, v.26, p.683- 690, 1997.

Lavezzo, W., Lavezzo, Oenm, \& Neto, O. C.. Estádio de Desenvolvimento do Milho. 1. Efeito sobre a Produção, Composição da Planta e Qualidade da Silagem. Revista da Sociedade Brasileira de Zootecnia, v. 26 , n. 4, p. 675-682, 1997 b.

Medeiros, S.R., \& Albertini, T.Z. Partição de energia e sua determinação na nutrição de bovinos de corte. In: Medeiros, S.R., Gomes, R.C., Bungenstab, D.J.(Eds.). Nutrição de Bovinos de Corte: Fundamentos e aplicações. Brasília, DF, EMBRAPA, 2015, 176p.

Mertens, D.R. Regulation of forage intake. In: FAHEY JR., G.C. (Ed.) Forage quality, evaluation and utilization. Winsconsin: American Society of Agronomy, 1994. p.450-493.

Nussio, L. G. Cultura de milho para produção de silagem de alto valor alimentício. In: SIMPÓSIO SOBRE NUTRICCÃO DE BOVINOS, 4., 1991, Piracicaba. Resumos... Piracicaba: FEALQ, p.59-168, 1991.

Oliveira, L. B. D., Pires, A. J. V. U., Carvalho, G. G. P. D., Ribeiro, L. S. O. U., Almeida, V. V. D., \& Peixoto, C. A. D. M. U. Perdas e valor nutritivo de silagens de milho, sorgo Sudão, sorgo forrageiro e girassol. Revista Brasileira de Zootecnia, v.39, n. 1, p.61-67, 2010. 
Pires, A.V.J, Reis R.A, Carvalho G.G.P, Siqueira G.R, Bernardes T.F, Ruggieri A.C, \& Roth M.T.P. Degradabilidade ruminal da matéria seca, da proteína bruta e da fração fibrosa de silagens de milho, de sorgo e de Brachiaria brizantha. Arquivo Brasileiro de Medicina Veterinária e Zootecnia, v.62, p.391-400, 2010.

Possenti, R.A., Ferrari Jr., E., \& Bueno, M.S. Parâmetros bromatológicos e fermentativos das silagens de milho e girassol. Ciência Rural, v.35, p. 1185-1189, 2005.

Qiu, X, Eastrigde, M.L., \& Wang, Z. Effects of corn silage hybrid and dietary concentration of forage NDF on digestibility and performance by dairy cows. Journal of Dairy Science, v.86, p.3667-3674, 2003.

Restle, J., Neumann, M., \& Brondani, I.L. Manipulação da altura de corte da planta de milho (Zea mays, L.) para ensilagem visando a produção do novilho superprecoce. Revista Brasileira de Zootecnia, v.31, p.1235-1244, 2002.

Rodrigues, P. H. M., De Gouvêa Pedroso, S. B., Melotti, L., De Andrade, S. J. T., \& De Lima, F. R. Estudo comparativo de diferentes tipos de silos sobre a composição bromatológica e perfil fermentativo da silagem de milho. Acta Scientiarum. Animal Sciences, v.24, p. 1127-1132, 2002.

Rosa, J.R.P., Silva, J.H.S., Restle, J., Pascoal, L.L., Brondani, I.L., Alves, Filho, D.C., \& Freitas, A.K. Avaliação do comportamento agronômico da planta e valor nutritivo da silagem de diferentes híbridos de milho (Zea mays L). Revista Brasileira de Zootecnia, v.33, p.302-312, 2004.

Roth, G., \& Undersanders, D. Silage additives. Corn silage production management and feeding. Madison: ASA, p.27-29, 1995.

Tedeschi, L. O., Fox, D. G., Pell, A. N., Lanna, D. P. D., \& Boin, C.. Development and evaluation of tropical feed library for The Cornell
Net Carbohydrate and Protein System model. Scientia Agricola, v.59, n. 1, p. 1-18, 2002.

Valadares Filho, S.C., Rocha Jr., V.R., \& Cappelle, E.R. Tabelas brasileiras de composição de alimentos para bovinos. Viçosa: Universidade Federal de Viçosa, 2002.

Van Soest, P.J. Factors influencing the voluntary intake of herbage by ruminants: voluntary intake in relation to chemical composition and digestibility. Journal of Animal Science, v.24 p.834-43, 1965.

Van Soest, P.J., Robertson J.B., \& Lewis, B.A. Methods for dietary fiber, neutral detergent fiber and non-starch polysaccharides in relation to animal nutrition. Journal Dairy Science, v.74, p. 3583-3597, 1991.

Van Soest, P.J. Nutritional ecology of the ruminant. 2.ed. Ithaca: Cornell University Press, 1994. 476p.

Velho, J.P., Muhlbach, P.R.F., Nornberg, J.L., Velho, I.M.P.H., Genro, T.C.M., \& Kessler, J.D. Composição bromatológica de silagens de milho produzidas com diferentes densidades de compactação. Revista Brasileira de Zootecnia, v.36, n.5, p. 1532-1538, 2007.

Vilela, D., Ferreira, R. P., Fernandes, E. N., \& Juntolli, F. V. Pecuária de leite no Brasil: Cenários e avanços tecnológicos. EMBRAPA, 2016. 435p.

Villela, T.E.A. Época de semeadura e de corte de plantas de milho para silagem. 2001. 80p.Tese (Doutorado) - Universidade Federal de Lavras, Lavras, 2001.

Wattiaux, M. A., \& Karg, K. L. Protein level for alfalfa and corn silage based diets. II. Nitrogen balance and manure characteristics. Journal of Dairy Science, v.87, p.3492-3502, 2006. 